International Journal of Instruction e-ISSN: 1308-1470 • www.e-iji.net

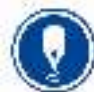

January $2021 \bullet$ Vol.14, No.1

p-ISSN: 1694-609X

pp. 161-180

Article submission code:

20191120125716

Received: 20/11/2019

Revision: $12 / 06 / 2020$

Accepted: 30/06/2020

OnlineFirst: 11/10/2020

\title{
Visual and Kinaesthetic Instructional Cues and Deaf People's Motor Learning
}

\section{Silmara Cristina Pasetto}

Escola de Educação Física e Esporte, Universidade de São Paulo, Brazil, silmap@uol.com.br

\section{João Manuel Pardal Barreiros}

Faculdade de Motricidade Humana, Universidade de Lisboa, Portugal, jbarreiros@fmh.ulisboa.pt

\section{Umberto Cesar Corrêa}

Prof., Escola de Educação Física e Esporte, Universidade de São Paulo, Brazil, umbertoc@usp.br

\section{Andrea Michele Freudenheim}

Escola de Educação Física e Esporte, Universidade de São Paulo, Brazil, amfreud@usp.br

This study investigated the effects of visual and kinaesthetic instructional cues separately and in combination on the learning of motor skills by individuals with deafness. In addition, whether the mastery level of sign language would affect motor skill learning was also investigated. The task was dart throwing. The sample consisted of 69 students of elementary education, of both sexes, as follows: 43 individuals with bilateral sensorineural hearing loss (from moderate/severe to anacusis) and 26 individuals who hear. The design involved three cue groups of instructional cues: visual, kinaesthetic, and visual and kinaesthetic. The study also comprised the following phases: pretest, acquisition; post-test; and transfer test. During the acquisition phase, the cue 'elbow flexed at $90^{\circ}$ ' was through figure (visual), manipulation (kinaesthetic) or both in conjunction. Results showed that the visual group obtained smaller absolute and variable errors in the transfer test than the kinaesthetic and visual-kinaesthetic groups, and no differences were observed among groups of individuals who hear. It was concluded that: (i) the visual cue was more efficient in promoting the motor learning of the individuals with deafness than the kinaesthetic and visual-kinaesthetic cues; (ii) the effects of the visual cue were specific to the learning of the individuals with deafness in comparing to individuals who hear; and (iii) the mastery level of sign language did not affect the occurrence or failure of motor skill learning.

Keywords: instruction, cue, attention, teaching, motor skills, dart throwing

Citation: Pasetto, S. C., Barreiros, J. M. P., Corrêa, U. M., \& Freudenheim, A. M. (2021). Visual and Kinaesthetic Instructional Cues and Deaf People's Motor Learning. International Journal of Instruction, 14(1), 161-180. https://doi.org/10.29333/iji.2021.14110a 


\section{INTRODUCTION}

Deafness is more common than one might think. According to the World Health Organization (WHO, 2018), more than 400 million individuals worldwide have deafness. It refers to a sensory deficit of hearing loss that results in the restriction of communication through oral language. A deaf individual is one unable to hear as well as someone with typical hearing (Marschark \& Hauser, 2012; Paul \& Whitelaw, 2011).

As with any complex phenomenon, deafness has been investigated from different perspectives (e.g. medical and educational) and analysis levels (e.g. social, behavioural, and neurological) (Cawthon \& Garberoglio, 2017; Marschark \& Hauser, 2012). The main concern in the researches is related to interventions to diminish its functional (e.g. delayed development of spoken language and academic performance), socio-affective (e.g. isolation and frustration), and socio-economic (e.g. health and educational costs) impacts. Although the complexity of deafness implies significant diversity among deaf individuals (Gannon, 2011), it is often said that the deaf have their own culture (Jassal, 2016), which extends to sportive events (Kurková, Valková \& Scheetz, 2011). The main assumptions in sport contexts is that participation plays an important role in diminishing the foregoing deafness impacts, and that it has the learning of motor skills in physical education classes as a sine qua non component (Hartman et al., 2011, Kurková et al., 2011). Motor skills are recognized as an educational subject because they are cultural constructions that human beings have adapted and practised in order to fulfil biological, psychological, and social needs: health, competition and leisure (Corrêa et al., 2016).

In the last few decades, a number of studies have been developed in order to understand the key aspects of the successful performance of motor skills by individuals with deafness, mainly related to perception. This refers to the process by which individuals pick up and interpret sensory information or how they deal with the information necessary for controlling their interactions with their performance's environment (Magill \& Anderson, 2017). Regarding to this, findings from three main research lines have together pointed to importance of specific instruction in directing the learner's attention during learning process. First, studies have indicated the existence of perceptual alterations due to deafness; they have pointed out that there is an improvement in peripheral visual perception in comparison to individuals who hear, which results from adaptive and compensatory changes related to neural maturation (e.g. Dye et al., 2007; Sladen et al., 2005).

Second, in a similar vein a number of studies have considered the mastery of sign language as an important aspect interacting with visual perception in individuals with deafness (e.g. Bavelier et al., 2001). It has been hypothesized that the mastery of sign language contributes to the improvement in peripheral visual perception as signalling movements change in the way they dynamically involve various spatial positions in a short time (Parasnis \& Samar, 1985), which requires both central and peripheral visual attention (Sladen et al., 2005). In fact, it has been reported that lack of exposure to sign language can be detrimental to intellectual, emotional, social, and motor development of deaf individuals (Capovilla, 2000; Lacerda \& Mantelatto, 2000). However, the few 
studies that are dedicated to testing this hypothesis have not provided evidence to support it (e.g. Dye et al., 2009).

Third, in addition to visual perception, researchers have addressed how performances of individuals with deafness are affected by kinaesthesia. In the present study, the term 'kinaesthetic perception' has been used to encompass the perception of skin touch (skin receptor), tactile perception and joint movements (Magill \& Anderson, 2017; Schmidt, Lee, Winstein, Wulf \& Zelaznik, 2018). Unlike vision, which is a unitary sense, kinaesthesia includes the combination of information from several receptors that integrate information on the kinaesthetic perception of the neuromuscular system (e.g. vestibular apparatus, muscle spindles, Golgi tendon organs, skin receptors) (Reily, 2003). Importantly, kinaesthetic information can also be perceived passively, that is, from aid and/or movement orientation through external manipulation (Schmidt et al., 2018). Regarding this matter, studies have investigated the hypothesis that there is an improvement in individuals with deafness' kinaesthetic perception in comparison to individuals who hear due to the activation of distinct cortical areas, as well as the mastery of sign language (e.g. Bolognini et al., 2011; Conway et al., 2011). However, results remain inconclusive. For example, whereas Levänen and Hamdorf (2001) showed that there was an increased kinaesthetic perception in the condition of congenital deafness in relation to that of individuals who hear, Heimler and Pavani (2014) revealed no change for the kinaesthetic perception of either the individuals with deafness and who hear.

Notwithstanding the advances in the comprehension of perception of individuals with deafness provided by the foregoing researches, it is important to note that the improvement in their peripheral visual perception may be a disadvantage when distracting stimuli at the periphery of the visual field become concurrent with the relevant stimuli of the central visual field. As a consequence, this may result in the difficulty of maintaining the focus on the relevant aspects of the task presented in the central field of vision with the resulting degradation of performance in learning tasks (Dye et al., 2009). These findings highlight the importance of the utilization of instructional strategies of selective attention related to the relevant aspects of the task (i.e. cues) during the learning of individuals with deafness (Pasetto et al., 2006).

In fact, instruction is conceived as a fundamental procedure of teaching, since it enables communicating with the learner about task goal and key aspects for successful performance (Edwards, 2010; Newell \& Ranganathan, 2010; Rink, 2010; Schmidt et al., 2018). This assumption extends to the learning by individuals with deafness, since the effectiveness of learning is closely related to the teacher's capability to select and communicate the instruction (Scheetz, 2012). Therefore, we expect that understanding how individuals with deafness deal with different cues can help teachers select the most relevant instruction - visual or kinesthetic - to promote effective learning of motor skills.

In sum, hearing loss put the visual and kinaesthetic perceptions as important informational variables for performance. However, there is still a lack of research into if and how both could together benefit the learning of individuals with deafness by directing their attention to relevant aspects of motor skills. Therefore, we sought to 
investigate the effects of different types of instructional cues (visual and kinaesthetic) on the learning of motor skills by individuals with deafness. We hypothesized that: (a) learning that relies on both visual and kinaesthetic cues together would be superior to each being provided separately; (b) such effects would be specific to the learning of the individuals with deafness compared to the individuals who hear; and (c) the effects would be influenced by the mastery of sign language.

\section{METHOD}

\section{Participants}

The sample comprised 69 students of elementary school, of both sexes, as follows: 43 with bilateral sensorineural hearing loss (from moderate/severe to anacusis) and 26 individuals who hear, with an average age of 10.4 years $( \pm 1.5)$ and 10.8 years $( \pm 1.4)$, respectively. Exclusion criteria for both participants with deafness and who hear were the use of medicines and the presence of motor and cognitive impairments that could compromise performance or, in the absence of these aspects, were not able to improve performance throughout practice as a basic learning characteristic. In addition, they could not have any previous experience in the learning task. All individuals participated voluntarily, and the parents' consent was obtained through the school management where the study was carried out, as approved by the local Institutional Review Board at the University of São Paulo ( $n^{\circ}$ 46102015.1.0000.5391).

\section{Task}

The learning task was dart throwing. This task was used because it: (i) is a motor skill of real context, which allowed motivation and novelty for learning; (ii) made possible measurable and clear environmental goals; (iii) involved a consistent experimental protocol related to instruction and motion analysis (e.g. Santos, Bastos, Souza \& Corrêa, 2014); and (iv) comprised four clearly distinguishable components that allowed accurate data of the movement pattern to be captured (posture, grip, position of the arm and throwing).

\section{Materials}

The task was performed with darts for beginners $-10.5 \mathrm{~cm} / 8$ grams (Gold Sport) with metal tip - and semi-professional darts (Nautika) in stainless steel, brass and ABS (acrylonitrile butadiene styrene) of $14.5 \mathrm{~cm} / 20$ grams. The darts were positioned $10 \mathrm{x}$ $20 \mathrm{~cm}$ EVA (ethyl vinyl acetate) board glued to a $0.7 \mathrm{~m}$ high MDF ( $0.7 \mathrm{~m}$ medium density fibreboard) table at a distance of $0.6 \mathrm{~m}$ from the (imaginary) centreline next to the hand of the participant (Figure 1). We also used two cameras (Cássio Exilim EXFH100 - 10.1 megapixels) fixed on tripods (Figure 1). Styrofoam markers were placed on the shoulder (major tuber), elbow (lateral epicondyle), and wrist (between the styloid process of the radius and ulna). The Launcher Tracker version 4.91 was the software used to obtain the measure of error related to the target (radial error). And, Kinovea software version 8.2 was used for the measures of time, space and angle relative to the movement pattern. 


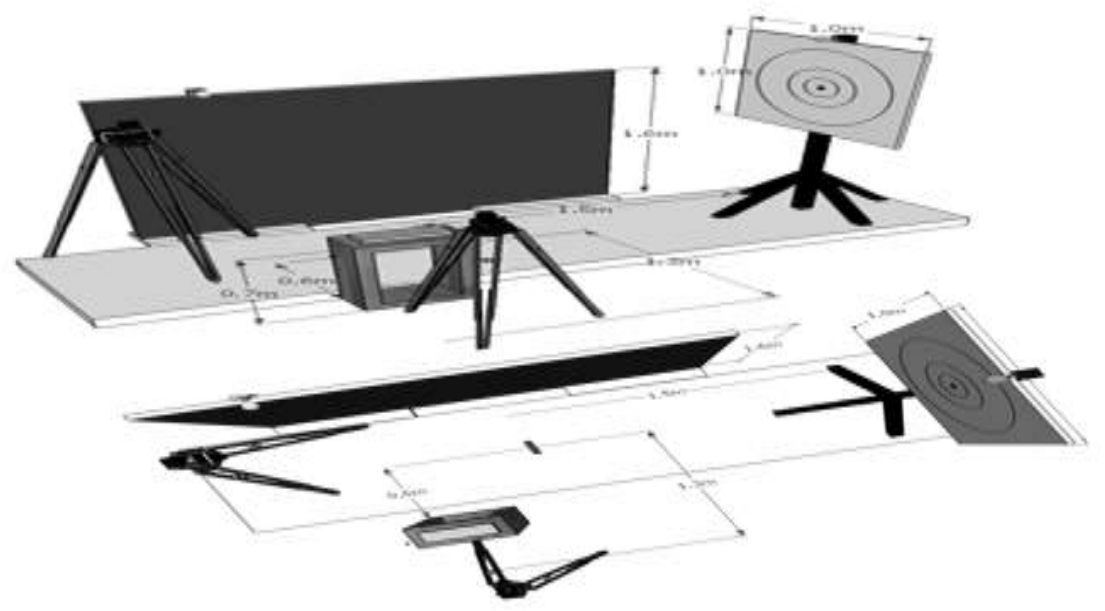

Figure 1

Illustration of the data collection environment, involving cameras 1 and 2, target, screen, darts support, and lights

\section{Data Procedures}

Besides literature related to the learning and performance of dart throwing as cited above, the content / focus of the cue, the number of trials, and the learning test were determined based on pilot studies.

In order to homogenize the groups, an intentional distribution of participants was made according to age, sex and schooling. The study consisted of three experimental groups composed of individuals with deafness: visual cue (V-D; $\mathrm{n}=16)$; kinaesthetic cue (KC$\mathrm{D} ; \mathrm{n}=13$ ); and, visual and kinaesthetic cues (VKC-D; $\mathrm{n}=14$ ). For each experimental group, a control group was composed of age-matched individuals who hear: visual cue $(\mathrm{V}-\mathrm{H} ; \mathrm{n}=9)$; (2) kinaesthetic cue $(\mathrm{KC}-\mathrm{H} ; \mathrm{n}=9)$; and, (3) visual and kinaesthetic cues (VKC-H; $\mathrm{n}=8$ ).

The experiment comprised four phases: a pretest with 5 throws without cue; acquisition, comprising 6 blocks of 10 throwing (different-coloured darts were used to register the blocks) with the respective cue being supplied; post-test, identical to the pretest, i.e. five throws without cue; and a transfer test with 10 throws at the same distance of the acquisition phase, but using semi-professional darts. In previous phases, the darts used were for beginners.

Data collection took place in the participants' schools, in a place specially made available for this purpose. Environments with low auditory and visual noise were designed to allow attention to be focused on the relevant aspect of the task. Participants were individually taken to the collection place and then received general information comprising: 
1. The importance of participating in a study on learning to throw darts, the purpose of which was to understand how deaf individuals would learn to throw darts at the target;

2. The goal of the game, i.e. to hit the centre of the target - in red -the closer to the centre of the target, the better.

3. The need for much practice and attention to be able to hit the centre of the target.

4. The importance of paying attention in the video-task, because it presented the general idea of movement through a real model (expert).

General information was provided orally to the hearer participants, and translated into LIBRAS for deaf participants, both through video recorded by the same interpreter. After the general information had been given, the specific instruction was provided, also through the video-task for all participants. Participants were asked to pay attention on: 1) how to hold the dart (hilt); 2) the position of the feet; 3) the arm position; and, 4) the movement of the arm during the throw. This procedure took place twice: the first time, the participant only watched; at the second time, he/she was instructed to perform the movement of throwing, positioned facing the target with the dart in the dominant hand, concomitantly to the presentation of the video-task, in a form of imitation. After the second visualization of the video-task, the experimenter made the anatomical marks on the participant's throwing arm.

After that, the experimenter explained (in LIBRAS for the deaf and orally for the hearer participants) the amount and organization of practice. Participants were also informed they would throw one dart at a time and they could only remove the dart from the stand with the dominant hand when the green light from the upper centre of the target lit up (Figure 1). After that, the experimenter verified the participants' understanding. During the acquisition phase, at the beginning of each trial block, the cue 'elbow flexed at $90^{\circ}$ ' was provided through a figure (Figure 2) (visual), manipulation (kinaesthetic) or both in conjunction.

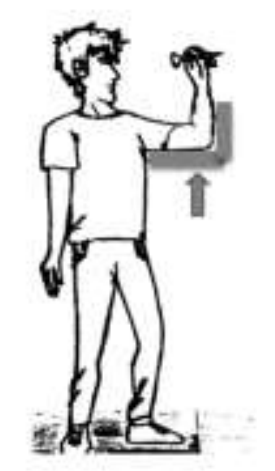

Figure 2

Illustration of the visual cue "elbow flexed at 90 " in the figure 
At the end of the throw (dart at the target) the green light turned off, and after 5 seconds the dart was removed from the target and only then did the light come on again, permitting the participant to take the next dart from the support. This interval was adequate for feedback processing (Swinnen, Schmidt, Nicholson, \& Shapiro, 1990).

The classroom teacher (certified teacher of the deaf) evaluated all the deaf participants regarding the LIBRAS 20 days after the data collection. A cadre of figures for the application of TVRSL 1.3 was distributed to the participants, who interpreted the signals and marked their responses with an ' $\mathrm{X}$ '.

\section{Data analysis}

The radial error referred to the performance measure related to the task goal, i.e. the distance $(\mathrm{cm})$ between the dart to the centre of the target. This measure was analysed with respect to accuracy and consistency as the hallmarks of motor skills, through the absolute and variable errors, respectively.

The performance was also analysed in relation to the response patterns through measures related to the time for responding (i.e. time for initiating the movement) and movement pattern. These measures enabled the inference to be made regarding the participants' engagement with the information processing and how they used the provided cued information for organizing or controlling their movement patterns in order to achieve the task goal. For this purpose, we considered the arithmetic mean in the same blocks as mentioned previously.

Time for responding:

a) Dart pick time: interval (seconds) between the green light on and the withdrawal of the dart.

b) Time of preparation for the throw: interval (seconds) between the withdrawal of the dart and initiation of the throw.

\section{Movement pattern:}

a) Initial angle $\left({ }^{\circ}\right)$ formed between the arm and forearm in the initial position of the arm.

b) Height of the elbow relative to the shoulder $(\mathrm{cm})$ at the initial position of the arm.

c) Angle of elbow flexion $\left(^{\circ}\right.$ )prior to the beginning of elbow extension.

d) Angle of elbow extension $\left(^{\circ}\right)$ at the end of the throw.

e) Angle of forearm flexion displacement $\left(^{\circ}\right)$.

f) Angle of forearm extension displacement $\left(^{\circ}\right)$.

g) Total angle of forearm displacement $\left(^{\circ}\right.$ ) (sum of the angles of flexion and extension of the elbow).

h) Elbow flexion time (s). 
i) Elbow extension time (s).

j) Total time of forearm displacement (s) (sum of times of flexion and extension of the elbow).

k) Forearm flexion velocity $(\%)$.

1) Forearm extension velocity $(\%)$.

m) Total velocity of forearm displacement $(\%)$.

n) Trunk displacement: difference $(\mathrm{cm})$ between the trunk at the initial and final positions.

\section{Statistical Analyses}

Non-parametric inferential statistics were used for analyzing the accuracy and consistence of performance because the data did not meet the statistical assumptions of normality and homogeneity of variance. Friedman $\chi^{2}$ tests were run in each experimental group to verify differences between blocks of trials (pre-, post-, and transfer tests). When differences were revealed, the Wilcoxon test was used to locate them. KruskalWallis tests were applied to verify intergroup differences in each test (pre-, post-, and transfer tests) and, when found, the Mann-Whitney U test was used to locate them. Furthermore, Kruskal-Wallis tests were applied for the time for responding and movement pattern variables in order to verify intergroup differences in the transfer test.

In order to investigate the influence of mastery of sign language on the learning of individuals with deafness firstly we divided the percentage of correct answers of deaf individuals in the questions of TVRSL 1.3 according quartiles as the cut-off points (Altman \& Bland, 1994). Correct answers ranged from $21.22 \%$ to $78.79 \%$. From quartiles, the accuracy and consistency of performances were compared in each test (pre-, post-, and transfer) by Kruskal-Wallis tests. Similar procedures were run for higher and lower values of correct answers by median in order to verify whether its effects would interact with those of cues on learning. We also analysed the percentage in relation to group performance by Chi-square tests (expected vs. observed). This analysis allowed the verification of whether participants achieved the expected basic level.

For all analyses, the level of significance was set at $\mathrm{p}<0.05$, using STATISTICA ${ }^{\circledR} 12.0$ software (Stat Soft Inc., Tulsa, USA).

\section{RESULTS}

\section{Task Goal Measures}

Figure 3 shows the absolute and variable errors of all deaf and hearer groups in each test. Regarding the absolute error, Friedman $\chi^{2}$ tests revealed main effects for all deaf groups: V-D $\left[\chi^{2}(\mathrm{n}=16, \mathrm{df}=2)=13.875, p=0.001\right]$; VKC-D $\left[\chi^{2}(\mathrm{n}=14, \mathrm{df}=2)=\right.$ $16.71, p=0.001]$; KC-D $\left[\chi^{2}(\mathrm{n}=13, \mathrm{df}=2)=12.153, p=0.002\right]$. The Wilcoxon tests showed that all groups had superior absolute error in the pretest compared to the postand transfer tests $(p<0.05)$. This means that all groups improved the performance 
accuracy from pretest to post- and transfer test. For intergroup comparisons, the Kruskal-Wallis test revealed differences in the transfer test $[\mathrm{H}(\mathrm{n}=43$, df $=2)=8.548, p$ $=0.013]$. The Mann-Whitney U test showed that V-D group had inferior absolute error than KC-D and VKC-D $(p<0.05)$. These results allow us to infer that V-D group was more accurate than $\mathrm{KC}-\mathrm{D}$ and $\mathrm{VKC}-\mathrm{D}$ groups in the transfer test.

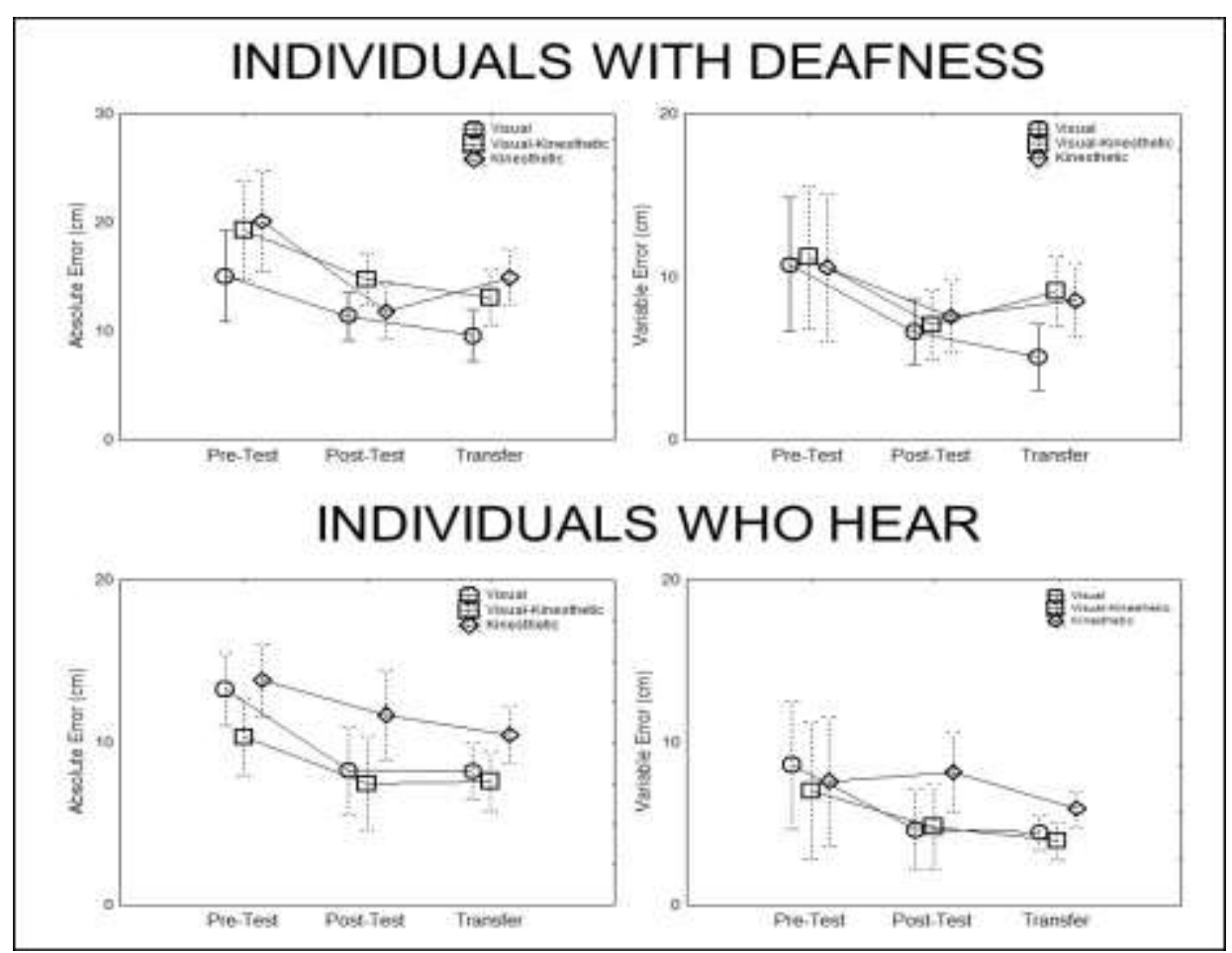

Figure 3

Absolute and variable errors $(\mathrm{cm})$ of deaf and hearer participants in the pre-, post-, and transfer tests

With relation to the hearer groups, Friedman $\chi^{2}$ tests also revealed main effects for all groups: $\mathrm{V}-\mathrm{H}\left[\chi^{2}(\mathrm{n}=9, \mathrm{df}=2)=13.555, p=0.001\right] ; \mathrm{VKC}-\mathrm{H}\left[\chi^{2}(\mathrm{n}=8, \mathrm{df}=2)=9.250\right.$, $p=0.009] ; \mathrm{KC}-\mathrm{H}\left[\chi^{2}(\mathrm{n}=9, \mathrm{df}=2)=8.666, p=0.013\right]$. The Wilcoxon tests showed that all groups had absolute error in the pretest greater than in the transfer test $(p<$ 0.05). This means that all groups improved the performance accuracy from pretest to post- and transfer test. Concerning the intergroup comparisons, the Kruskal-Wallis test revealed main effects in the pre- $[\mathrm{H}(\mathrm{n}=26, \mathrm{df}=2)=5.843, p=0.05]$ and transfer tests $[\mathrm{H}(\mathrm{n}=26, \mathrm{df}=2)=5.790, p=0.05]$. In these cases, Mann-Whitney U tests showed that VKC-H had superior absolute error to $\mathrm{KC}-\mathrm{H}(p<0.05)$. These results allow us to infer that $\mathrm{KC}-\mathrm{H}$ group was more accurate than VKC-D group. 
With respect to the variable error, Friedman $\chi^{2}$ tests did not reveal main effects for deaf groups. However, the Kruskal-Wallis test revealed intergroup effects in the transfer test $[\mathrm{H}(\mathrm{n}=43, \mathrm{df}=2)=8.662, p=0.013]$. The Mann-Whitney U test showed that V-D had smaller variable error than the remaining groups $(p<0.05)$. That is, performance of V-D group was more consistent than the remaining groups in the transfer test.

Similarly, Friedman $\chi^{2}$ tests did not reveal main effects for hearer groups. And, the Kruskal-Wallis test revealed main effects in the transfer test $[\mathrm{H}(\mathrm{n}=26, \mathrm{df}=2)=6.694$, $p=0.035]$. The Mann-Whitney test showed that $\mathrm{KC}-\mathrm{H}$ had greater variable error than the remaining groups $(p<0.05)$. These results allow us to infer that the performance of $\mathrm{KC}-\mathrm{H}$ was more inconsistent than those of remaining groups in the transfer test.

\section{Response Patterns Measures}

Table 1 shows means and standard deviations of all measures of response patterns.

Table 1

Mean (M) and standard deviation (SD) response pattern measures of visual (V), kinesthetic $(\mathrm{KC})$, and visual and kinesthetic (VKC) cues groups of individuals with deafness and who hear.

\begin{tabular}{|c|c|c|c|c|c|c|c|}
\hline & \multicolumn{2}{|c|}{ Individuals With Deafness } & \multicolumn{5}{|c|}{ Individuals Who Hear } \\
\hline & & Pre-test & Post-test & Transfer & Pre-test & Post-test & Transfer \\
\hline Measure & Groups & $M \pm S D$ & $M \pm S D$ & $M \pm S D$ & $M \pm S D$ & $M \pm S D$ & $M \pm S D$ \\
\hline \multirow[t]{3}{*}{ Dart pick time } & $\mathrm{V}$ & 3.9 & $4.4 \pm 1.7$ & $4.5 \pm 1.5$ & $2.5 \pm 1.1$ & $2.6 \pm 1.1$ & $3.6 \pm 1.0$ \\
\hline & $\mathrm{VKC}$ & $4.0 \pm 1.1$ & $3.8 \pm 1.9$ & $3.3 \pm 1.0$ & $2.4 \pm 1.0$ & $2.3 \pm 1.4$ & $3.4 \pm 1.4$ \\
\hline & $\mathrm{KC}$ & $3.4 \pm 1.8$ & $4.5 \pm 1.9$ & $3.5 \pm 1.1$ & $3.1 \pm 1.8$ & $3.3 \pm 0.9$ & $4.5 \pm 2.3$ \\
\hline Preparation & $\mathrm{V}$ & $8.0 \pm 6.5$ & $8.2 \pm 5.8$ & $7.7 \pm 3.1$ & $9.2 \pm 5.6$ & $8.4 \pm 3.6$ & $9.8 \pm 4.8$ \\
\hline \multirow[t]{2}{*}{ Time } & $\mathrm{VKC}$ & $8.7 \pm 4.9$ & $8.6 \pm 5.4$ & $10.7 \pm 7.2$ & $8.4 \pm 2.8$ & $11.3 \pm 4.2$ & $10.9 \pm 3.7$ \\
\hline & $\mathrm{KC}$ & $7.5 \pm 2.4$ & $6.9 \pm 2.6$ & $8.1 \pm 3.1$ & $10.3 \pm 4.9$ & $10.8 \pm 3.4$ & $12.8 \pm 4.6$ \\
\hline \multirow[t]{3}{*}{ Initial angle } & $\mathrm{V}$ & $102.3 \pm 35.2$ & $89.9 \pm 22.0$ & $84.0 \pm 17.7$ & $74.8 \pm 27.9$ & $70.2 \pm 15.8$ & $69.4 \pm 12.5$ \\
\hline & $\mathrm{VKC}$ & $79.0 \pm 27.6$ & $69.0 \pm 26.6$ & $65.4 \pm 18.6$ & $77.3 \pm 33.0$ & $87.1 \pm 12.6$ & $75.8 \pm 11.5$ \\
\hline & $\mathrm{KC}$ & $81.8 \pm 38.8$ & $73.5 \pm 26.8$ & $59.8 \pm 14.6$ & $63.3 \pm 21.0$ & $82.6 \pm 15.9$ & $74.4 \pm 9.6$ \\
\hline Height elbow- & $\mathrm{V}$ & $42.5 \pm 20.8$ & $25.2 \pm 22.0$ & $20.9 \pm 17.0$ & $29.7 \pm 16.4$ & $14.1 \pm 7.5$ & $11.1 \pm 6.8$ \\
\hline \multirow[t]{2}{*}{ shoulder } & $\mathrm{VKC}$ & $26.5 \pm 17.1$ & $14.3 \pm 14.0$ & $9.2 \pm 7.4$ & $38.0 \pm 19.3$ & $14.8 \pm 13.3$ & $12.3 \pm 7.8$ \\
\hline & $\mathrm{KC}$ & $33.6 \pm 20.0$ & $17.5 \pm 14.9$ & $15.4 \pm 9.9$ & $25.9 \pm 10.1$ & $13.9 \pm 6.0$ & $11.2 \pm 5.2$ \\
\hline Trunk & $\mathrm{V}$ & $25.0 \pm 9.7$ & $20.8 \pm 14.9$ & $20.9 \pm 10.9$ & $26.4 \pm 7.2$ & $17.0 \pm 8.3$ & $16.9 \pm 9.2$ \\
\hline \multirow[t]{2}{*}{ movement } & $\mathrm{VKC}$ & $20.4 \pm 8.9$ & $12.7 \pm 6.6$ & $12.6 \pm 6.4$ & $28.6 \pm 12.9$ & $18.2 \pm 6.1$ & $18.9 \pm 5.0$ \\
\hline & $\mathrm{KC}$ & $23.7 \pm 9.5$ & $14.1 \pm 9.3$ & $16.4 \pm 9.9$ & $27.3 \pm 9.4$ & $19.1 \pm 9.1$ & $20.0 \pm 6.9$ \\
\hline Angle of elbow & $\mathrm{V}$ & $77.7 \pm 39.0$ & $55.8 \pm 27.6$ & $50.8 \pm 18.2$ & $50.1 \pm 26.2$ & $36.0 \pm 14.5$ & $32.2 \pm 13.1$ \\
\hline \multirow[t]{2}{*}{ flexion } & $\mathrm{VKC}$ & $56.3 \pm 37.5$ & $42.2 \pm 20.1$ & $35.9 \pm 14.2$ & $47.0 \pm 21.3$ & $46.0 \pm 13.5$ & $35.9 \pm 13.9$ \\
\hline & $\mathrm{KC}$ & $61.2 \pm 45.7$ & $54.0 \pm 28.3$ & $37.9 \pm 17.3$ & $35.0 \pm 24.4$ & $46.9 \pm 11.1$ & $37.0 \pm 8.2$ \\
\hline Angle of elbow & $\mathrm{V}$ & $72.9 \pm 10.1$ & $65.5 \pm 11.8$ & $67.3 \pm 11.2$ & $65.3 \pm 13.2$ & $61.7 \pm 10.2$ & $63.2 \pm 10.6$ \\
\hline \multirow[t]{2}{*}{ extension } & VKC & $77.1 \pm 15.1$ & $72.5 \pm 13.7$ & $71.0 \pm 10.0$ & $58.6 \pm 14.3$ & $64.4 \pm 11.1$ & $63.5 \pm 8.9$ \\
\hline & $\mathrm{KC}$ & $71.4 \pm 16.0$ & $78.2 \pm 16.8$ & $78.6 \pm 12.5$ & $58.8 \pm 12.5$ & $59.2 \pm 10.4$ & $58.1 \pm 7.6$ \\
\hline Angle of & $\mathrm{V}$ & $4.8 \pm 2.3$ & $3.6 \pm 1.7$ & $3.3 \pm 1.1$ & $2.6 \pm 0.9$ & $2.4 \pm 0.8$ & $3.1 \pm 2.9$ \\
\hline forearm & VKC & $3.5 \pm 2.1$ & $2.5 \pm 1.0$ & $2.3 \pm 0.7$ & $3.5 \pm 1.4$ & $3.3 \pm 0.9$ & $2.9 \pm 0.5$ \\
\hline
\end{tabular}




\begin{tabular}{|c|c|c|c|c|c|c|c|}
\hline flexion & $\mathrm{KC}$ & $4.1 \pm 3.1$ & $3.1 \pm 2.6$ & $2.3 \pm 1.1$ & $2.7 \pm 0.9$ & $3.6 \pm 1.5$ & $2.6 \pm 0.4$ \\
\hline Angle of forearm & $\mathrm{V}$ & $142.2 \pm 49.1$ & $110.7 \pm 21.4$ & $112.7 \pm 27.0$ & $104.4 \pm 28$ & $95.9 \pm 11.9$ & $94.2 \pm 13.3$ \\
\hline \multirow[t]{2}{*}{ extension } & $\mathrm{VKC}$ & $124.0 \pm 50.9$ & $108.1 \pm 16.1$ & $98.1 \pm 17.7$ & $98.3 \pm 17.1$ & $107.8 \pm 13.3$ & $96.2 \pm 17.3$ \\
\hline & $\mathrm{KC}$ & $123.7 \pm 52.2$ & $114.2 \pm 24.5$ & $106.1 \pm 21.7$ & $88.2 \pm 26.5$ & $100.9 \pm 14.0$ & $91.9 \pm 9.3$ \\
\hline Total angle of & $\mathrm{V}$ & $23.3 \pm 9.7$ & $18.9 \pm 7.8$ & $20.2 \pm 5.8$ & $21.1 \pm 9.8$ & $19.9 \pm 8.5$ & $19.6 \pm 9.5$ \\
\hline \multirow[t]{2}{*}{ forearm } & $\mathrm{VKC}$ & $18.3 \pm 8.1$ & $17.7 \pm 6.0$ & $17.0 \pm 5.9$ & $16.0 \pm 6.9$ & $18.7 \pm 7.5$ & $16.4 \pm 6.8$ \\
\hline & $\mathrm{KC}$ & $21.4 \pm 11.6$ & $23.6 \pm 11.5$ & $18.7 \pm 4.9$ & $16.4 \pm 14.2$ & $18.2 \pm 5.5$ & $18.3 \pm 4.3$ \\
\hline Elbow flexion & $\mathrm{V}$ & $93.0 \pm 25.3$ & $94.5 \pm 29.4$ & $86.6 \pm 20.4$ & $108.7 \pm 33$ & $132.1 \pm 80.0$ & $132.3 \pm 77$ \\
\hline \multirow[t]{2}{*}{ time } & $\mathrm{VKC}$ & $107.3 \pm 26.6$ & $121.5 \pm 31.4$ & $112.3 \pm 34.8$ & $85.8 \pm 27.5$ & $104.2 \pm 22.0$ & $88.6 \pm 16.4$ \\
\hline & $\mathrm{KC}$ & $99.4 \pm 26.0$ & $114.2 \pm 30.1$ & $105.4 \pm 22.8$ & $86.5 \pm 35.6$ & $119.9 \pm 29.8$ & $94.9 \pm 18.0$ \\
\hline Elbow & $\mathrm{V}$ & $43.9 \pm 14.6$ & $45.1 \pm 13.4$ & $41.2 \pm 8.9$ & $56.7 \pm 29.7$ & $79.3 \pm 105.7$ & $48.9 \pm 14.0$ \\
\hline \multirow[t]{2}{*}{ extension time } & $\mathrm{VKC}$ & $50.3 \pm 13.7$ & $55.4 \pm 26.8$ & $52.9 \pm 18.0$ & $36.4 \pm 13.8$ & $39.3 \pm 10.4$ & $37.9 \pm 8.8$ \\
\hline & $\mathrm{KC}$ & $48.1 \pm 18.6$ & $60.4 \pm 22.7$ & $60.6 \pm 24.2$ & $38.7 \pm 14.6$ & $38.6 \pm 7.7$ & $40.1 \pm 4.4$ \\
\hline Total time of & $\mathrm{V}$ & $4.0 \pm 2.3$ & $3.0 \pm 1.5$ & $2.6 \pm 1.0$ & $2.2 \pm 1.2$ & $1.8 \pm 0.7$ & $1.7 \pm 0.4$ \\
\hline \multirow[t]{2}{*}{ forearm } & $\mathrm{VKC}$ & $2.9 \pm 2.1$ & $2.2 \pm 0.9$ & $2.1 \pm 0.8$ & $3.2 \pm 1.7$ & $2.7 \pm 0.8$ & $2.3 \pm 0.4$ \\
\hline & $\mathrm{KC}$ & $2.7 \pm 1.5$ & $2.6 \pm 2.3$ & $2.2 \pm 0.9$ & $2.2 \pm 1.2$ & $3.2 \pm 1.6$ & $2.1 \pm 0.4$ \\
\hline Forearm flexion & $\mathrm{V}$ & $1.0 \pm 0.3$ & $0.8 \pm 0.3$ & $1.0 \pm 0.3$ & $0.7 \pm 0.3$ & $0.6 \pm 0.2$ & $1.5 \pm 2.7$ \\
\hline \multirow[t]{2}{*}{ velocity } & $\mathrm{VKC}$ & $0.8 \pm 0.3$ & $0.7 \pm 0.3$ & $0.8 \pm 0.3$ & $0.8 \pm 0.4$ & $0.7 \pm 0.2$ & $0.8 \pm 0.2$ \\
\hline & $\mathrm{KC}$ & $1.7 \pm 3.0$ & $0.8 \pm 0.3$ & $0.8 \pm 0.3$ & $0.9 \pm 0.5$ & $0.5 \pm 0.1$ & $0.7 \pm 0.2$ \\
\hline Forearm & $\mathrm{V}$ & $33.0 \pm 13.2$ & $39.0 \pm 11.6$ & $38.7 \pm 13.5$ & $35.7 \pm 4.4$ & $35.0 \pm 6.1$ & $38.5 \pm 6.9$ \\
\hline extension & $\mathrm{VKC}$ & $31.3 \pm 18.8$ & $36.7 \pm 13.2$ & $38.3 \pm 14.5$ & $37.6 \pm 16.2$ & $42.0 \pm 16.1$ & $43.1 \pm 14.0$ \\
\hline velocity & $\mathrm{KC}$ & $29.5 \pm 12.5$ & $32.9 \pm 7.8$ & $32.3 \pm 9.2$ & $33.8 \pm 11.4$ & $38.6 \pm 10.5$ & $40.5 \pm 8.5$ \\
\hline Total velocity & $\mathrm{V}$ & $104.6 \pm 10.7$ & $104.5 \pm 12.4$ & $106.1 \pm 9.7$ & $101.0 \pm 12$ & $96.7 \pm 13.3$ & $101.6 \pm 11$ \\
\hline \multirow[t]{2}{*}{ of forearm } & $\mathrm{VKC}$ & $106.3 \pm 17.5$ & $109.1 \pm 13.4$ & $109.3 \pm 12.2$ & $96.2 \pm 13.0$ & $106.4 \pm 13.2$ & $106.6 \pm 12$ \\
\hline & $\mathrm{KC}$ & $100.9 \pm 12.2$ & $111.1 \pm 12.8$ & $110.9 \pm 9.5$ & $92.6 \pm 14.0$ & $97.9 \pm 13.8$ & $98.6 \pm 10.8$ \\
\hline
\end{tabular}

\section{Time for Responding}

Dart pick time. The Kruskal-Wallis test revealed intergroup effects in the transfer test $[\mathrm{H}(\mathrm{n}=36, \mathrm{df}=2)=8.094, p=0.017]$. The Mann-Whitney U test showed that V-D had greater time between the lamp lighting and picking up the dart than the other groups $(p<$ 0.05). Regarding the hearer groups, Friedman $\chi^{2}$ tests revealed main effects only for $\mathrm{KC}-\mathrm{H}\left[\chi^{2}(\mathrm{n}=4, \mathrm{df}=2)=6.000, p=0.049\right]$. The Wilcoxon test showed that the time between the lamp lighting and picking up the dart in the post-test was smaller than in the transfer test $(p<0.05)$. These results allow us to infer that V-D group took longer to catch the dart than the other groups and that $\mathrm{KC}-\mathrm{H}$ increased the time for catching the dart from post- to transfer test.

\section{Movement Pattern}

(a) Initial angle. The Kruskal-Wallis revealed intergroup effects in the post- $[\mathrm{H}(\mathrm{n}=43$, $\mathrm{df}=2)=6.066, p=0.048]$ and transfer test $[\mathrm{H}(\mathrm{n}=43, \mathrm{df}=2)=13.575, p=0.001]$. The Mann-Whitney U tests pointed out that V-D had greater initial angle than VKC-D (posttest) and VKC-D and KC-D (transfer) $(p<0.05)$. 
(b) Height of the elbow relative to the shoulder. The intragroup analyses revealed main effects for all deaf groups: V-D $\left[\chi^{2}(\mathrm{n}=16\right.$, df $\left.=2)=14.451, p=0.000\right]$; VKC-D $\left[\chi^{2}(\mathrm{n}\right.$ $=14, \mathrm{df}=2)=10.714, p=0.004] ; \mathrm{KC}-\mathrm{D}\left[\chi^{2}(\mathrm{n}=13, \mathrm{df}=2)=14.307, p=0.000\right]$. The Wilcoxon tests pointed out that in the pretest all groups had height of the elbow relative to the shoulder greater than in the post-test; moreover, it was revealed that this last one was greater than in the transfer test $(p<0.05)$.

With relation to the listener groups, the intragroup analyses revealed main effects for all groups: V-H $\left[\chi^{2}(\mathrm{n}=9, \mathrm{df}=2)=6.222, p=0.044\right]$; VKC-H $\left[\chi^{2}(\mathrm{n}=8, \mathrm{df}=2)=7.750, p\right.$ $=0.020] ; \mathrm{KC}-\mathrm{H}\left[\chi^{2}(\mathrm{n}=9, \mathrm{df}=2)=8.666, p=0.013\right]$. The Wilcoxon tests also showed that in the pretest all groups had the height of the elbow relative to the shoulder greater than in the post-test; moreover, this last one was greater than in the transfer test ( $\mathrm{p}<$ $0.05)$.

(c) Trunk displacement. The Friedman $\chi^{2}$ tests revealed effects only for KC-D group $\left[\chi^{2}(\mathrm{n}=13, \mathrm{df}=2)=11.230, p=0.003\right]$. The Wilcoxon showed that trunk displacement in the pretest was greater than in the post- and transfer test $(p<0.05)$.

Regarding the hearer groups, Friedman $\chi^{2}$ tests revealed effects only for $\mathrm{VKC}-\mathrm{H}\left[\chi^{2}(\mathrm{n}=\right.$ $8, \mathrm{df}=2)=7.7500, p=0.020]$. The Wilcoxon test showed that the trunk displacement in the pretest was greater than in the post- and transfer tests.

(d) Angle of elbow extension. The Friedman $\chi^{2}$ tests revealed intragroup effects only for VKC-H $\left[\chi^{2}(\mathrm{n}=16, \mathrm{df}=2)=9.250, p=0.009\right]$. The Wilcoxon test showed that the angle of elbow extension in the pretest was smaller than in the post- and transfer tests $(p$ $<0.05)$

(e) Angle of forearm flexion displacement. The Kruskal-Wallis test revealed intergroup effects in the transfer test $[\mathrm{H}(\mathrm{n}=43, \mathrm{df}=2)=5.792, p=0.05]$. The Mann-Whitney $\mathrm{U}$ test showed that V-D had a greater angle of forearm flexion displacement than VKC-D group $(p<0.05)$.

(f) Angle of forearm extension displacement. With relation to the intragroup comparisons, main effects were revealed only for V-D $\left[\chi^{2}(\mathrm{n}=16\right.$, $\mathrm{df}=2)=5.809, p=$ $0.05]$. The Wilcoxon test showed that the angle of forearm extension displacement in the pretest was greater than in the post-test $(p<0.05)$.

(g) Elbow flexion time. The Kruskal-Wallis test revealed intergroup effects for hearers in the post- $[\mathrm{H}(\mathrm{n}=26, \mathrm{df}=2)=5.939, p=0.051]$ and transfer tests $[\mathrm{H}(\mathrm{n}=23, \mathrm{df}=2)=$ $5.848, p=0.053]$. The Mann-Whitney $\mathrm{U}$ test showed that $\mathrm{V}-\mathrm{H}$ had smaller elbow flexion time than $\mathrm{KC}-\mathrm{H}$ (post-test) and $\mathrm{VKC}-\mathrm{H}$ (transfer) $(p<0.05)$.

(h) Elbow extension time. Regarding the hearer groups, Friedman $\chi^{2}$ tests revealed effects only for $\mathrm{KC}-\mathrm{H}\left[\chi^{2}(\mathrm{n}=16\right.$, $\left.\mathrm{df}=2)=6.888, p=0.031\right]$. The Wilcoxon test showed that the elbow extension time in the post-test was smaller than in the pre- and transfer tests $(p<0.05)$. 
(i) Total time of forearm displacement. The Kruskal-Wallis test revealed intergroup effects in the transfer test $[\mathrm{H}(\mathrm{n}=43, \mathrm{df}=2)=6.642, p=0.036]$. The Mann-Whitney U test showed that V-D had greater total time of forearm displacement than remaining groups $(p<0.05)$. No intra and intergroup effects were revealed for hearer groups.

(j) Forearm extension velocity. The Kruskal-Wallis test revealed intergroup effects in the post- $[\mathrm{H}(\mathrm{n}=43, \mathrm{df}=2)=7.362, p=0.025]$ and transfer tests $[\mathrm{H}(\mathrm{n}=43, \mathrm{df}=2)=$ $6.812, p=0.033]$. The Mann-Whitney $\mathrm{U}$ test showed that V-D had smaller forearm extension velocity than $\mathrm{KC}-\mathrm{D}(p<0.05)$.

Concerning the hearer groups, Friedman $\chi^{2}$ tests revealed intragroup effects only for $\mathrm{KC}-\mathrm{H}\left[\chi^{2}(\mathrm{n}=8, \mathrm{df}=2)=8.000, p=0.0183\right]$. The Wilcoxon test showed that the forearm extension velocity in the pre- was smaller than in the post- and transfer tests $(p$ $<0.05)$. And intergroups analyses revealed effects in the transfer test $[\mathrm{H}(\mathrm{n}=26, \mathrm{df}=2)$ $=5.944, p=0.05]$. The Mann-Whitney $\mathrm{U}$ test showed that $\mathrm{V}-\mathrm{H}$ had greater forearm extension velocity than VKC-H $(p<0.05)$.

(k) Total velocity of forearm displacement. Friedman $\chi^{2}$ tests revealed intragroup effects only for KC-D $\left[\chi^{2}(\mathrm{n}=12, \mathrm{df}=2)=6.000, p=0.049\right]$. The Wilcoxon test showed that the total velocity of forearm displacement in the pretest was smaller than in the post-test $(p<0.05)$. With relation to intergroup comparisons, the Kruskal-Wallis test revealed effects in the post- $[\mathrm{H}(\mathrm{n}=43, \mathrm{df}=2)=5.830, p=0.054]$ and transfer tests $[\mathrm{H}(\mathrm{n}=43, \mathrm{df}$ $=2)=8.054, p=0.017]$. The Mann-Whitney U test showed that V-D had smaller total velocity of forearm displacement than KC-D $(p<0.05)$.

\section{Mastery of LIBRAS}

Concerning the mastery level of LIBRAS, no differences were revealed for accuracy and consistency in the pre-, post- and transfer tests. Furthermore, results of the Chi-square test revealed that observed correct answers were different (inferior) to those expected answers $\left(\chi^{2}=420.99\right.$, $\left.\mathrm{df}=65, p<0.05\right)$. These results mean that performance was not affected by the by the levels at which learners mastered the LIBRAS, and that they did not show the expected level of performance.

\section{DISCUSSION}

Over the past few decades there has been increasing interest in research on education of individuals with deafness, including themes related to language development stages, sign language, diversity within the deaf community, educational settings, hearing aids and cochlear implants, bilingual communication, cognitive processes and teacher skills (Luckner \& Carter, 2001; Marschark \& Spencer, 2010; Marschark, Tang, \& Knoors, 2014; Scheetz, 2012). However, not much attention has been paid on learning of motor skills as an essential educational component. The aim of the study was to investigate: (i) the effects of providing visual and kinaesthetic instructional cues, both separately and together, on learning motor skills of individuals with deafness; (ii) whether such effects would be specific to the learning of the individuals with deafness; and (iii) whether the mastery of LIBRAS would influence the effects of visual, kinaesthetic, and visual 
associated with kinaesthetic cues on the learning of a motor skill by individuals with deafness.

Results showed that the visual instructional cue made possible a superior learning of the dart throwing by individuals with deafness in comparison to the kinaesthetic cues only and visual associated with kinaesthetic cues. This finding is based on the fact that the visual group obtained smaller absolute and variable errors in the transfer test than the kinaesthetic and visual-kinaesthetic groups.

Visual information is recognized as critical to the performance of a variety of motor skills, being considered as the 'queen of the senses' (Cornsweet, 2012; Gibson, 2014; Mann, Causer, Nakamoto, \& Runswick, 2019; Schmidt et al., 2017; Snowden, Thompson, \& Troscianko, 2012; Vickers, 2011). According these authors, vision allows the defining of the physical structure of the environment and provides information about the displacement of objects and spatial and temporal aspects of movement itself in the environment. It is possible that the visual cue allows one to visualize at a glance spatial aspects and details of movement, which probably would be expressed by kinaesthetic cues, only with more difficulty. Proteau (1992) states that static visual cues (e.g. figures) presented before the beginning of movement play an important role in its planning. In this vein, it was verified that deaf learners of the visual cue group (figure) presented a response pattern related to the dart pick time greater than the other groups. Probably, the visual cue group had engaged itself more in the planning of the movement than the remaining groups. Furthermore, this group showed a positioning of the throwing arm with the elbow flexed near to $90^{\circ}$, and the cue provided was specifically about the initial position of the angle of the throwing arm $\left(90^{\circ}\right)$. It appeared that this behaviour interfered directly in the following variables such as: angle of forearm flexion displacement; total time of forearm movement; forearm extension velocity; and total velocity of forearm displacement. It was inferred that the positioning closest to $90^{\circ}$ generated a greater angle of forearm flexion displacement, and consequently increased the total time of forearm displacement throughout the tests and reduced the forearm extension velocity.

However, the visual-kinaesthetic cues group also received the same visual cue provided to the visual cue group, but their results were similar to those of the kinaesthetic cue group. In this regard, it is possible to think that there may have been a conflict of sensory information for the learners with deafness of the group with associated information (visual-kinaesthetic cue), or that the concomitant kinesthetic cue harmed the use of the visual cue by the individuals with deafness. Perhaps a task is best learned if the instruction is presented via a single sensory modality (Carrasco, 2011; Klein \& Posner, 1974).

The studies with individuals who hear have also suggested that when visual and kinaesthetic information is available, visual information becomes dominant, that is, the processing of kinaesthetic information is affected by the presence of visual information (e.g. Johnson et al., 2006). For instance, the study by Johnson et al. (2006) showed that visual information provided increased kinaesthetic (haptic) sensitivity even when the specific (kinaesthetic) stimulus was not present, since the participants reported feeling the touch from the visual stimulus. 
Regarding the performance of the kinaesthetic cue group, it is possible that the kinaesthetic cue generated a passive movement that did not allow the formation of internal models of representation. According to Beets et al. (2012), passive movements (e.g. driven by others) are not accompanied by the generation of internal models because the learner cannot update and refine them through his/her own error detection/correction mechanism. These authors investigated the acquisition of motor skills through passive and active movements. They showed that the superiority of the active movement group was a consequence of a more active participation in the processes of detection and correction of error, which allowed for planning and replanning processes of the movement, necessary for learning.

With regard to the question of whether the effects of visual, kinaesthetic, and visualkinaesthetic instructional cues are specific to the individuals with deafness' learning, the answer is 'yes'. This is because, whereas the visual cue was more efficient for participants with deafness's learning, no differences were observed among groups of individuals who hear in the transfer test. In addition, it was found that none of the three groups of individuals who hear changed the movement pattern relative to the cue about the positioning of the throwing arm with the elbow flexed close to $90^{\circ}$. It is possible to think that individuals who hear are less sensitive to the visual information when compared to individuals with deafness (Dye, et al., 2007; Dye et al., 2008; Heimler \& Pavani, 2014). It is also interesting to note that the behaviours of the groups of individuals who hear were inverse to those of the deaf in relation to the measure of forearm extension velocity.

Regarding the sign language, as previously stated, it has been investigated as an important variable related to visual (e.g. Bosworth et al., 2013; Bottari et al., 2010; Dye et al., 2009) and kinaesthetic perceptions (tactile / haptic) of the deaf (e.g. Conway et al., 2011; Heming \& Brown, 2005). The assumption here is that the movements during signaling vary dynamically in terms of different spatial positions in a short time (Parasnis \& Samar, 1985), which requires increased learner's visual attention, both central and peripheral, and also kinaesthetic perception (Sladen et al., 2005). However, the present study did not provide support for such an assumption. Firstly, because results showed no difference between the performances of individuals with deafness with upper and lower levels of sign language mastery. But, importantly it may have occurred because individuals with deafness presented an inferior mastery level compared to the expected level of Brazilian deaf individuals (Capovilla, 2000; Capovilla et al., 1998).

\section{CONCLUSION}

In sum, based on the objectives and delimitations of this study we can conclude that: (1) the visual instructional cue was more efficient in promoting the motor learning of the individuals with deafness than the kinaesthetic and visual-kinaesthetic cues; (2) the effects of the visual instructional cue were specific to the learning of the individuals with deafness in comparison to individuals who hear; and (3) the mastery level of LIBRAS was below that expected for age and schooling, which did not determine the occurrence of learning of a motor skill by individuals with deafness. 
In terms of future studies, our findings 'open a window' for investigations about whether, over the process of acquisition of individuals with deafness, there is a shift in the predominant use of visual information to that of kinaesthetic information. It is also important to investigate the effects of the different types of cue on the learning of motor skills of different natures, such as those whose result is the movement pattern by itself (e.g. pirouette or somersault). Finally, it is also indicated that a study should be developed that allows the question about the existence of an association between the mastery level of LIBRAS and the effects of the type of cue on the learning of motor skills to be looked at in more depth.

In general, it should be emphasized that deafness is one of the most frequent dysfunctions in the neonatal period (e.g. $2 \%$ of the Brazilian population). These data make it possible to study the effects of the different types of cue on the motor learning of the individuals with deafness as an avenue of relevant questions with population meaning. The results, besides contributing to the knowledge about the factors that affect the learning of motor skills of the individuals with deafness, can still serve as inspiration for the design of studies of an applied nature, as well as for the decision-making in the processes of motor intervention (teaching) with the individuals with deafness.

\section{DISCLOSURE STATEMENT}

No potential conflict of interest was reported by the authors.

\section{ACKNOWLEDGEMENTS}

This study was financed in part by the Coordenação de Aperfeiçoamento de Pessoal de Nível Superior - Brasil (CAPES) - Finance Code 001.

\section{REFERENCES}

Bavelier, D., Brozinsky, C., Tomann, A., Mitchell, T., Neville, H., \& Liu, G. (2001). Impact of early deafness and early exposure to sign language on the cerebral organization for motion processing. The Journal of Neuroscience, 21, 8931-8942.

Beets, I. A. M., Macé, M., Meesen, R. L. J., Cuypers, K., Levin, O., \& Swinnen, S. P. (2012). Active versus passive training of a complex bimanual task: Is prescriptive proprioceptive information sufficient for inducing motor learning? Plos One, 7, 1-11.

Bolognini, N., Cecchetto, C., Geraci, C., Maravita, A., Pascual-Heone, A., \& Papagno, C. (2011). Hearing shapes our perception of time: Temporal discrimination of tactile stimuli in deaf people. Journal of Cognitive Neuroscience, 24, 276-286.

Bosworth, R. G., Petrich, J. A. F., \& Dobkins, K. R. (2013). Effects of attention and laterality on motion and orientation discrimination in deaf signers. Brian and Cognition, $82,117-126$.

Bottari, D., Nava, E., Ley, P., \& Pavani, F. (2010). Enhanced reactivity to visual stimuli in deaf individuals. Restorative Neurology and Neuroscience, 28, 167-179. 
Burton, H., Videen, T. O., \& Raichle, M. E. (1993). Tactile-vibration-activated foci in insular and parietal-opercular cortex studied with positron emission tomography: Mapping the second somatosensory area in humans. Journal Somatosensory \& Motor Research, 10, 297-308.

Capovilla, F. C. (2000). Filosofias educacionais em relação ao surdo: Do oralismo à comunicação total ao bilinguismo. Revista Brasileira de Educação Especial, 6, 99-116.

Capovilla, F. C., \& Raphael, W. D. (2008). Dicionário enciclopédico ilustrado da lingua de sinais brasileira. São Paulo: Editora da Universidade de São Paulo.

Capovilla, F. C., Raphael, W. D. \& Macedo, E. C. (1998). Manual ilustrado de sinais e sistema de comunicação em rede para surdos. São Paulo: Instituto de Psicologia, USP.

Carrasco, M. (2011). Visual attention: The past 25 years. Vision Research, 51, 14841525.

Cawthon, S. W. \& Garberoglio, C. L. (Eds.). (2017). Research in deaf education: Contexts, challenges, and considerations (perspectives on deafness). New York: Oxford University Press.

Conway, C. M., Karpicke, J., Anaya, E. M., Henning, S. C., Kronenberger, W. G., \& Pisoni, D. B. (2011). Nonverbal cognition in deaf children following cochlear implantation: Motor sequencing disturbances mediate language delays. Developmental Neuropsychology, 36, 237-254.

Cornsweet, T. N. (2012). Visual perception. New York: Academic Press

Corrêa, U. C., Correia, W. R. \& Tani, G. (2016). Towards the teaching of motor skills as a system of growing complexity. In: M. Koopmans \& D. Stamovlasis. (Orgs.). Complex Dynamical Systems in Education: Concepts, Methods and Applications (pp. 93-103). New York: Springer.

De Oreo, K., \& Williams, H. G. (1980). Characteristics of kinesthetic perception. In C. B. Corbin \& K. De Oreo (Eds.). A textbook of motor development (pp. 174-196). Dubuque, Iowa: Wm. C. Brown.

Dye, M. W. G., \& Baril, D. E., \& Bavelier, D. (2007). Which aspects of visual attention are changed by deafness: The case of the attentional network test. Neuropsychology, 45, 1801-1811.

Dye, M. W. G., Houser, P. C., \& Bavelier, D. (2008). Visual skills and cross-modal plasticity in deaf readers: Possible implications for acquiring meaning from print. Annals of the New York Academy of Sciencis, 1145, 71-82.

Dye, M. W. G., Houser, P. C., \& Bavelier, D. (2009). Is visual selective attention in deaf individuals enhanced or deficient? The case of the useful field of view. Plos One, 4,5640 .

Gannon, G. R. (2011). Deaf heritage: A narrative history of deaf America. Washinton, DC: Gallaudet University Press. Dummer, G. M., Haubenstricker, J. L., \& Stewart, D. 
A. (1996). Motor skill performances of children who are deaf. Adapted Physical Activity Quarterly, 13, 400-414.

Gibson, J. J. (2014). The Ecological Approach to Visual Perception: Classic Edition. New York: Psychology Press.

Hartman, E., Houwen, S., \& Visscher, C. (2011). Motor skill performance and sports participation in deaf elementary school children. Adapted Physical Activity Quarterly, $28,132-145$.

Heimler, B., \& Pavani, F. (2014). Response speed advantage for vision does not extend to touch in early deaf adults. Experimental Brain Research, 1335-1342.

Heming, J. E. \& Brown, L. N. (2005). Sensory temporal processing in adults with early hearing loss. Brain and Cognition, 59, 173-182.

Heuer, H., \& Keele, S. W. (1996). Handbook of perception and action. Vol. 2, Motor skills. San Diego: Academic Press.

Jassal, Yasmine R. (2016). Learning about deaf culture: More accessible than previously thought. American Annals of the Deaf, 161, 583-584.

Johnson, R. M., Philip, C. B., \& Ro, T. (2006). Visually induced feelings of touch. Brain Research, 1126, 398-406.

Klein, R. M. \& Posner, M. I. (1974). Attention to visual and kinesthetic components of skills. Brain Research, 71, 401-411.

Kurková, P., Valková, H., \& Scheetz, N. (2011). Factors impacting participation of European elite deaf athletes in sport. Journal of Sports Sciences, 29, 607-618.

Lacerda, C. B. F., \& Mantelatto, S. A. C. (2000). As diferentes concepções de linguagem na prática fonoaudiológica. In C.B.F. Lacerda, H. Nakamura, \& M. C. Lima (Eds.), Fonoaudiologia: Surdez e abordagem bilíngue (pp. 23-43). São Paulo: Plexus.

Landin, D. (1994). The role of verbal cues in skill learning. Quest, 46, 299-313.

Levänen, S., \& Hamdorf, D. (2001). Feeling vibrations: Enhanced tactile sensitivity in congenitally deaf humans. Neuroscience Letters, 301, 75-77.

Luckner, J. (1991). Skills needed for teaching hearing impaired adolescents: The perception of teachers. American Annals of the Deaf, 136, 422-428.

Luckner, J. L., \& Carter, K. (2001). Essential competencies for teaching students with hearing loss and additional disabilities. American Annals of the Deaf, 146, 7-15.

Magill, R. A. \& Anderson, D. I. (2017). Motor learning and control: concepts and applications. $11^{\text {th }}$ ed. New York: McGraw-Hill.

Mann, D. L., Causer, J., Nakamoto, H., \& Runswick, O. R. (2019). Visual search behaviours in expert perceptual judgements. In A. M. Williams \& R. C. Jackson. Anticipation and decision making in sport (pp. 59-78). London: Routledge. 
Marschark, M. \& Hauser, P. (2012). How deaf children learn: What parents and teachers need to know (Perspectives on deafness). New York: Oxford University Press.

Marschark, M. \& Spencer, P. E. (2010). The oxford handbook of deaf studies, language, and education. Vol. 2. New York: Oxford University Press.

Marschark, M., Tang, G., \& Knoors, H. (2014). Bilingualism and bilingual deaf education. New York: Oxford University Press.

Neville, H. J. \& Lawson, D. (1986). Attention to central and peripheral visual space in a movement detection task: An event-related potential and behavioral study. II. Congenitally deaf adults. Brain Research, 405, 268-283.

Neville, H. J., \& Lawson, D. (1987). Attention to central and peripheral visual space in a movement detection task. III. Separate effects of auditory deprivation and acquisition of a visual language. Brain Research, 405, 284-294.

Parasnis, I., \& Samar, V. J. (1985). Parafoveal attention in congenitally deaf and hearing young adults. Brain and Cognition, 4, 313-327.

Pasetto, S. C., Araújo, P. F., \& Corrêa, U. C. (2006). Efeitos de dicas visuais na aprendizagem do nado crawl para alunos surdos. Revista Portuguesa de Ciências do Desporto, 6, 281-292.

Paul, P. V., \& Whitelaw, G. M. (2011). Hearing and deafness: An introduction for health and education professionals. Massachusetts: Jones and Bartlett Publishers, LLC.

Proteau, L. (1992). The specificity of learning and the role of visual information for movement control. In L. Proteau, \& D. Elliot (Eds.), Vision and motor control (pp. 67103). Amsterdam: North Holland

Reily, L. H. (2003). As imagens: O lúdico e o absurdo no ensino de arte para préescolares surdos. In I. R. Silva, S. Kanchakje, \& Z. M. Gesueli. (Eds.), Cidadania, surdez e linguagem: Desafios e realidades (pp. 161-192). São Paulo: Plexus.

Santos, J. J., Bastos, F. H., Souza, T. O., \& Corrêa, U. C. (2014). Contextual interference effect depends on the amount of time separating acquisition and testing. Advances in Physical Education, 4, 102-109.

Scheetz, N A. (2012). Deaf education in the 21st century. New York: Pearson.

Schmidt, R. A, Lee, T. D., Winstein, C., Wulf, G., \& Zelaznik, H. N. (2018). Motor control and learning: a behavioral emphasis. $6^{\text {th }}$ ed. Champaign: Human Kinetics.

Sladen, D. P., Tharpe, A. T., Ashmead, D. H. D., \& Grantham, W. (2005). Visual attention in deaf and normal hearing adults: Effects of stimulus compatibility. Journal of Speech, Language, and Hearing Research, 48, 1529-1537.

Snowden, R., Thompson, P., \& Troscianko, T. (2012). Basic Vision: An Introduction to Visual Perception. New York: Oxford University Press. 
Stewart, D. A. (1993). Deaf sport: The impact of sports within the deaf community. Washington, DC: Gallaudet University Press.

Swinnen, S. P., Schmidt, R. A., Nicholson, D. E., \& Shapiro, D. C. (1990). Information feedback for skill acquisition: Instantaneous knowledge of results. Journal of Experimental Psychology: Learning, Memory, and Cognition, 16, 706-716.

Vickers, J. N. (2011). Mind over muscle: the role of gaze control, spatial cognition, and the quiet eye in motor expertise. Cognition Processing, 12, 219-222. DOI 10.1007/s10339-011-0411-2

Williams, A. M., Davids, K., \& Williams, J. G. (1999). Visual perception and action in sport. New York: Routledge.

World Health Organization - WHO (2018). Deafness and hearing loss. Retrieved from http://www.who.int/mediacentre/factsheets/fs300/en/. April 2, 2018. 